\title{
The role of level and function of High Density Lipoprotein (HDL) in Cardiovascular Diseases
}

\author{
Malihe Aghasizadeh $^{1}$ (D), Majid Ghayour Mobarhan ${ }^{2,3}$ (D), Toba Kazemi4 ${ }^{4}$ (D), \\ Amir Avan ${ }^{2}$ Ebrahim Miri Moghaddam ${ }^{5}$
}

\author{
${ }^{1}$ Student Research Committee, Department of Molecular Medicine, Birjand University of Medical Sciences, Birjand, Iran \\ ${ }^{2}$ Department of Modern Science and Technology, Faculty of Medicine, Mashhad University of Medical Sciences, Mashhad, Iran. \\ ${ }^{3}$ UNESCO Higher Center, Nutrition Department, Mashhad University of Medical Sciences, Mashhad, Iran \\ ${ }^{4}$ Cardiovascular Diseases Research Center, Cardiology Department, Birjand University of Medical Sciences, Birjand, Iran \\ ${ }^{5}$ Corresponding author; Cardiovascular Disease Research Center, Department of Molecular Medicine, Birjand University of \\ Medical Sciences, Birjand, Iran \\ Tel: +9832381230 \\ E-mail: moghaddam4@yahoo.com
}

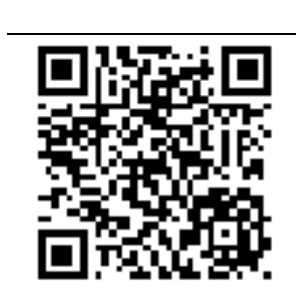

Citation Malihe Aghasizadeh M, Ghayour Mobarhan M, Kazemi T, Avan A, Miri Moghaddam E. [The Role of level and function of High Density Lipoprotein (HDL) in Cardiovascular Diseases]. J Birjand Univ Med Sci. 2020; 27(2): 118-27. [Persian]

DOI http://doi.org/10.32592/JBirjandUnivMedSci.2020.27.2.100

Received: February 29, 2020

Accepted: April 9, 2020

\begin{abstract}
High-density lipoprotein (HDL) is a set of particles with heterogeneous structures that have different functions due to various compounds including surface charge, size, lipid, and protein compounds. Several prospective epidemiological studies have demonstrated that there is a clear inverse relationship between serum HDL concentration and risk of coronary heart disease, despite this relationship, clinical evidence has only challenged the usefulness of higher levels of HDL-C in predicting the risk of cardiovascular diseases (CVD) and have proven that the structure of HDL is altered and loosed function. Therefore, extensive research is needed to identify new agents and biomarkers to improve HDL function and reduce the risk of cardiovascular disease. Given that the most important function of HDL is to transfer excess cholesterol from peripheral tissues and macrophage cells through a receptor called ABCA1 and direct it to the liver, plays an important role in protecting the formation of atherosclerotic plaque. This molecule can provide a strong protective effect against oxidative damage caused by free radicals with intermittent inhibition of the production of pro-inflammatory oxidized lipids in the intima layer of arteries. There is an inverse relationship between the ability to efflux cholesterol and the prevalence of CVD.

The ability to remove cholesterol from macrophages by HDL, it is a crucial criterion for determining HDL performance, and it has a strong inverse relationship with carotid intima-media thickness and coronary artery stenosis in angiography independent of HDL level.
\end{abstract}

Key Words: Atherosclerosis; Cardiovascular Disease; High Density Lipoprotein; Lipoprotein 


\title{
نقش سطح و عملكرد ليبوبروتئين با جكالى بالا (HDL) در بيمارىهاى قلبى- عروقى
}

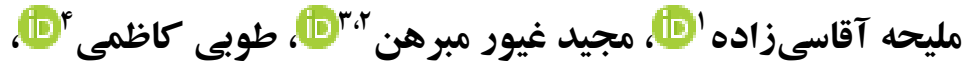

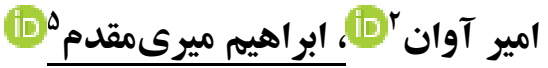

جكيده

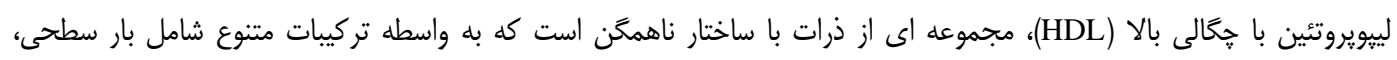

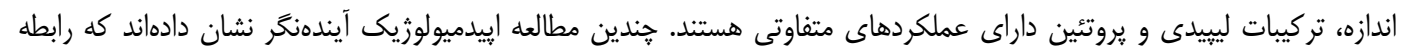

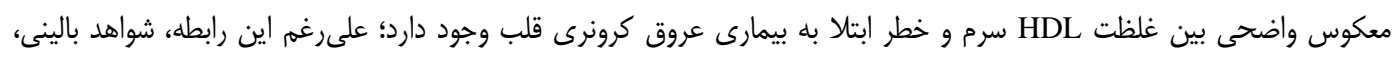

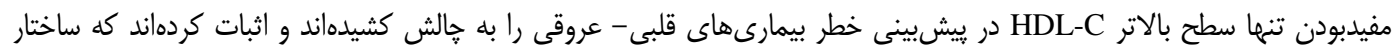

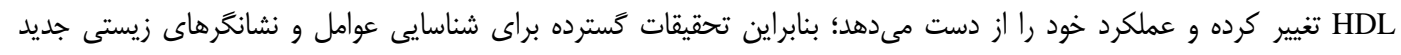

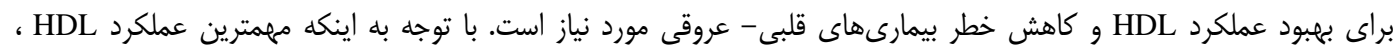

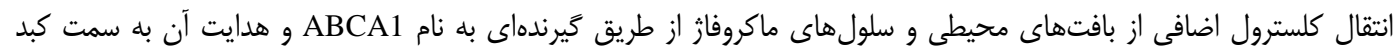

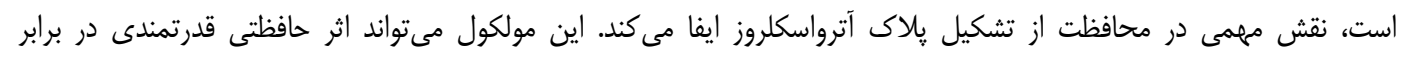

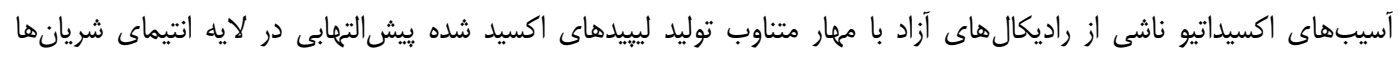

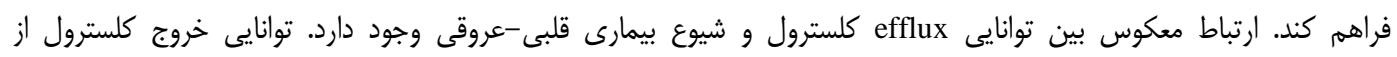

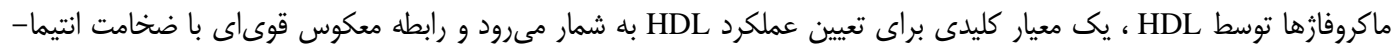

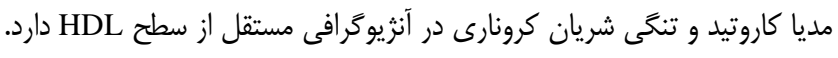
وازههاى كليدى: آتروسكلروزيس؛ بيمارىهاى قلبى - عروقى؛ لييويروتئين با جَالى بالا؛ ليبويروتئين

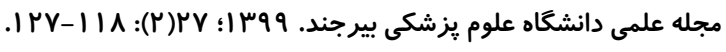

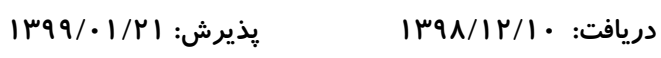


افزايشدهنده سطح HDL و يا مهار كندههاى Cholesteryl مقدمه ester transfer protein بعضى از بيماران مشاهده نشده است (^، V). اين نكته بسيار لائز اهميت است كه عملكرد و مكانيسم مولكولى HDL همراه با ارزيابى سطح آن براى (HDL functionality)

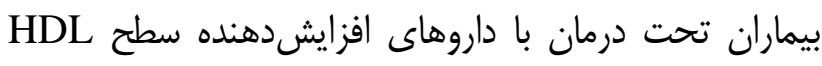

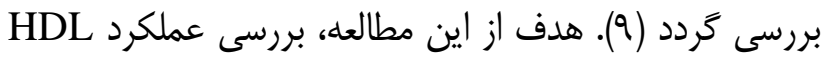
و ورشهاى اندازهگيرى آن است.

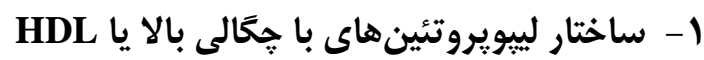

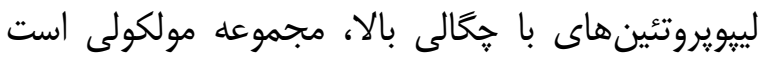

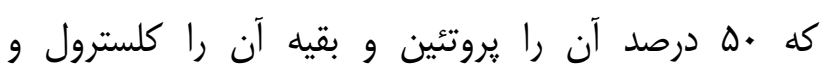

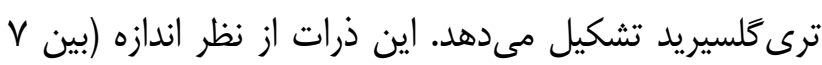

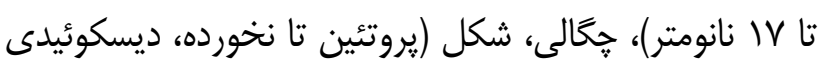

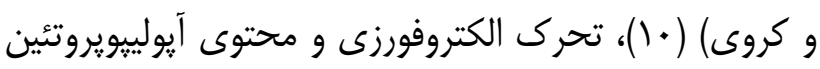

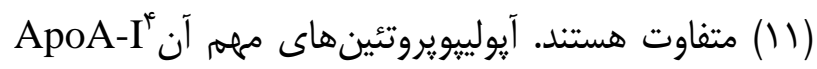

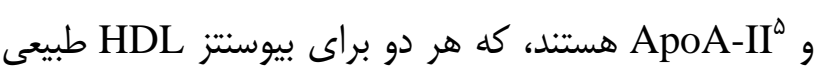
مورد نياز مىباشند. APO-AI در روده و كبد سنتز مىشود و

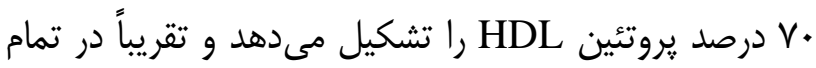

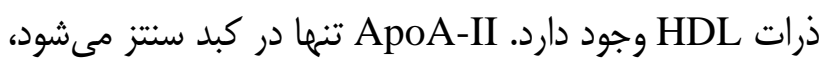

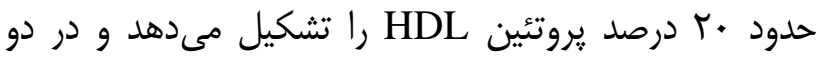
سوم ذرات HDL در انسان وجود دارد (rات). مطالعات طيفسنجى جرمى نشان مىدهد كه ذرات

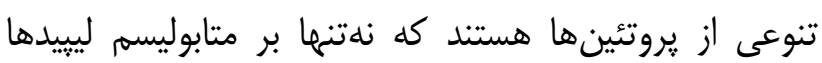
تأثير مى كذارد؛ بلكه در تنظيم مكمل، باسخخ فاز هاد هاد و در مهار

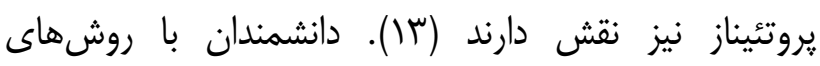

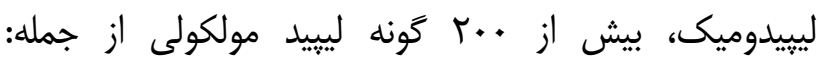
فسفولييبدها، اسفنكوليييدها، استروئيدها، كلسترولاسترها،

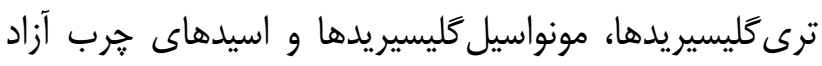

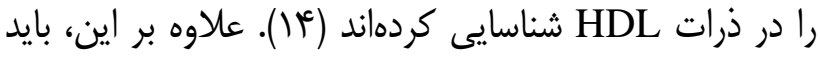

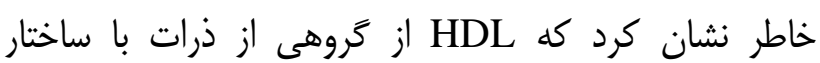

\footnotetext{
4 Apolipoprotein A-I

${ }^{5}$ Apolipoprotein A-II
}

بيمارى هاى قلبى - عروقى شايعترين علت مركى و مير در

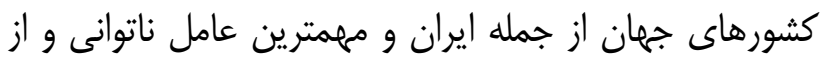

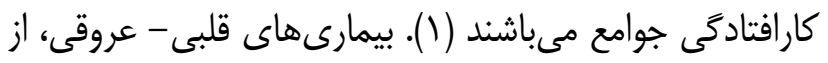

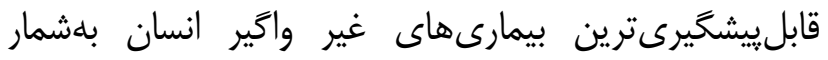

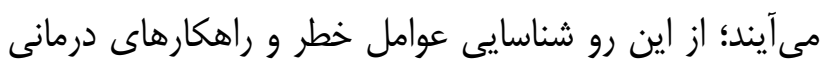
حائز اهميت است. عوامل خطر مستقل اين بين بيمارى شامل

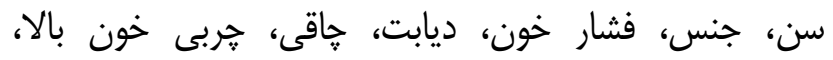

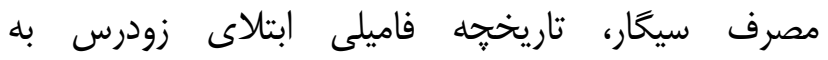

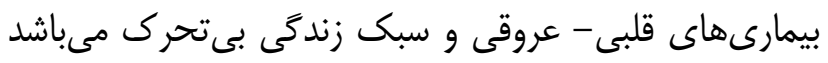

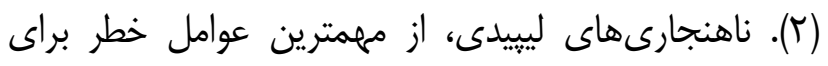

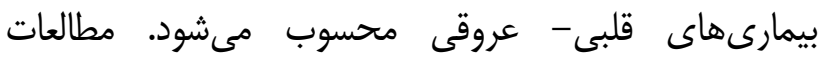
إييدميولوزيك نشان داده است كه يكى از عوامل خطر اسلى اسلى

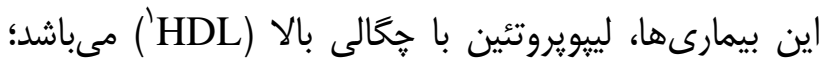

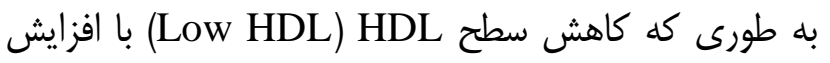
خطر اين بيمارىها ارتباط مستقيم دارد (بّ). غلظت كلسترول

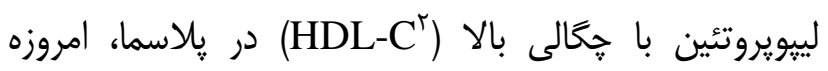

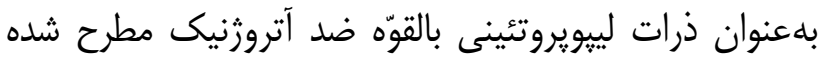

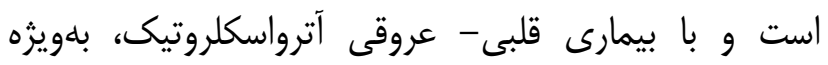
بيمارى عروق كرونر (CAD) بممراه است (أ).

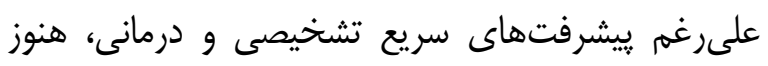

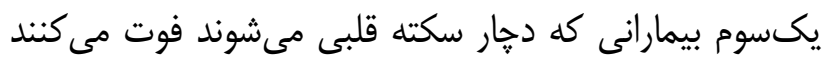

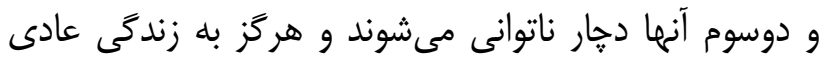

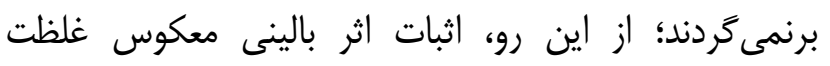
HDL-C

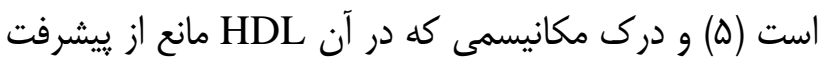

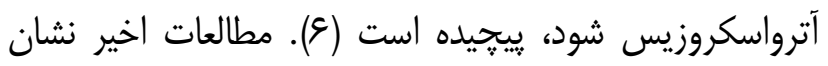
داده است كه سطح HDL بهتنهايى براى ارزيابى خطر ابتلا

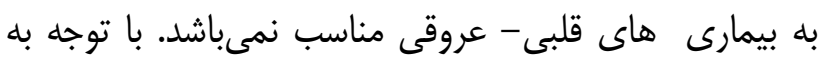
تحقيقات مختلف بالينى در ارتباط با اثر دارئ داروهاى

\footnotetext{
${ }^{1}$ High density lipoprotein

${ }^{2}$ High density lipoprotein - cholesterol

${ }^{3}$ Coronary artery disease
} 


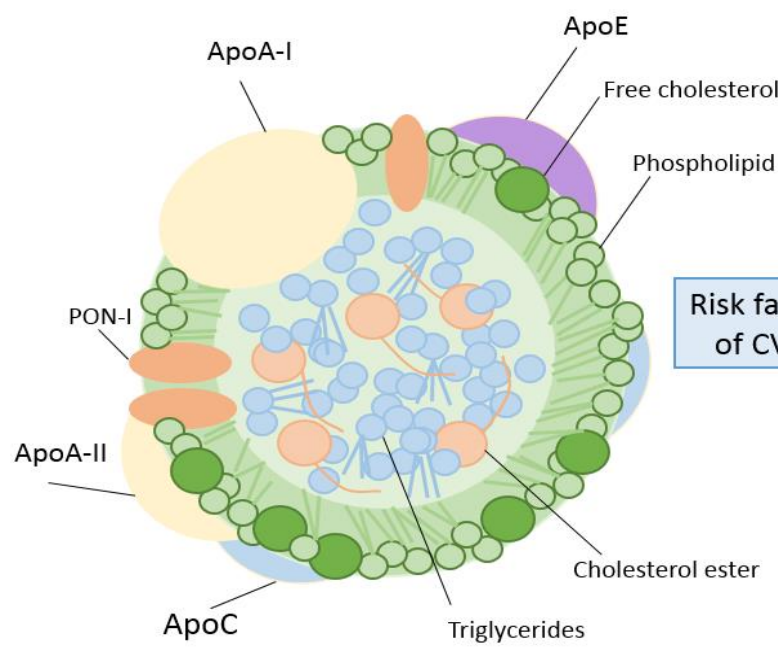

Normal HDL

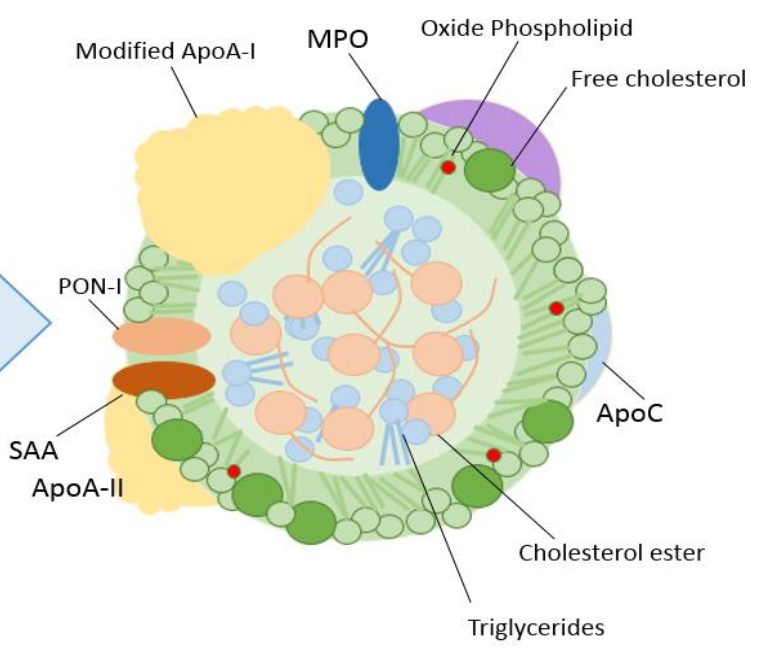

Dysfunctional HDL

شكل ا- ساختار HDL نرمال و HDL با عملكرد غير نرمال. ApoA-I: آيولييويروتئين AL؛ PLTP: يروتئين انتقالدهنده فسفوليييد؛ MPO:

ميلويراكسيداز؛ SAA سرم آميلوئيد A A (1)

ويزگكى بيولوزيكى مفيد ديخر نيز مىباشد كه باعث تقويت اثر

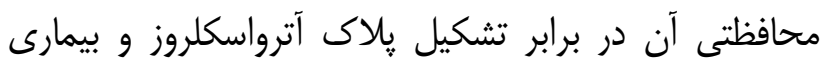

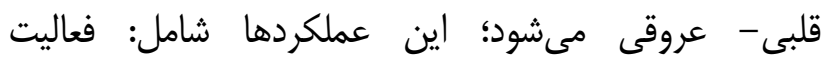

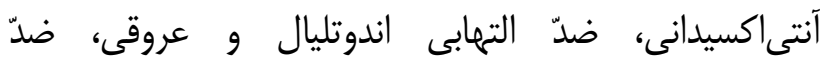

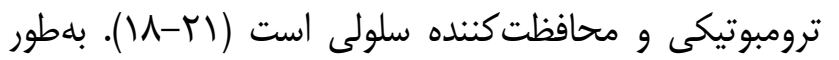
اختصاصى، HDL مىتواند يك محافظت قدرتمند در برابر

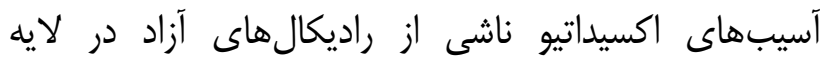

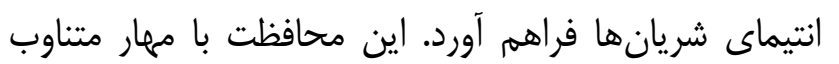

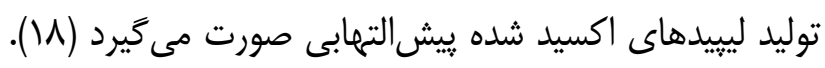

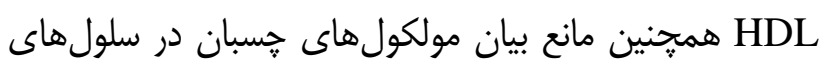

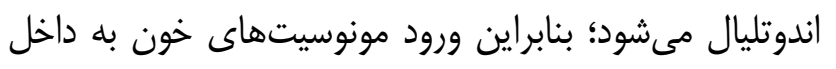

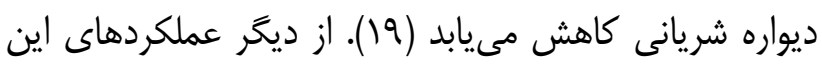

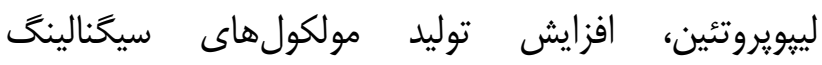

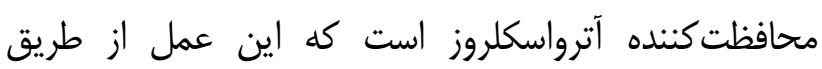

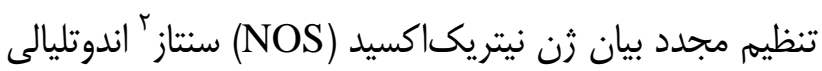

\footnotetext{
${ }^{2}$ Nitric oxide synthase
}

ناهمكن، فيزيوشيميايى، تركيبى و عملكردى مشخص و با

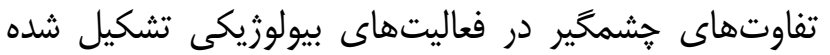

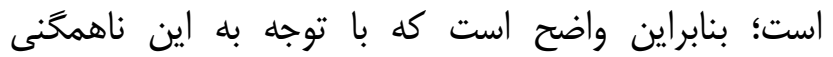

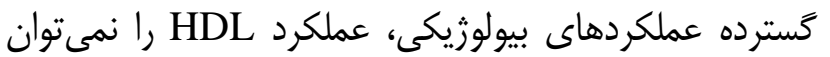

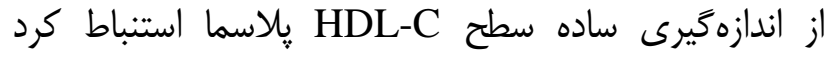
(1) (1). همانطور كه در شكل يك نشان داده شده است، ساختار HDL در اثر عوامل خطر بيمارىهاى قلبى - عروقى تغيير كرده و عملكرد خود را از دست مى دهد.

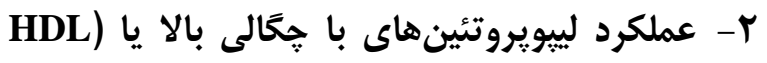

\section{:Functionality}

ذرات HDL، بلواسطه تركيبات متنوع تشكيلدهنده آنها داراى عملكردهاى متفاوتى هستند كه مىتوان ارتباط آنها رات آنتات

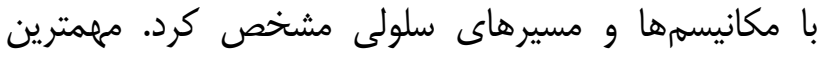
عملكرد آن، انتقال كلسترول اضافى از بافتها و هدائ هدايت آن آن

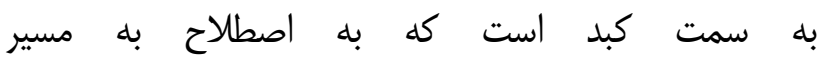
RCT '

\footnotetext{
${ }^{1}$ Reverse Cholesterol Transport
} 

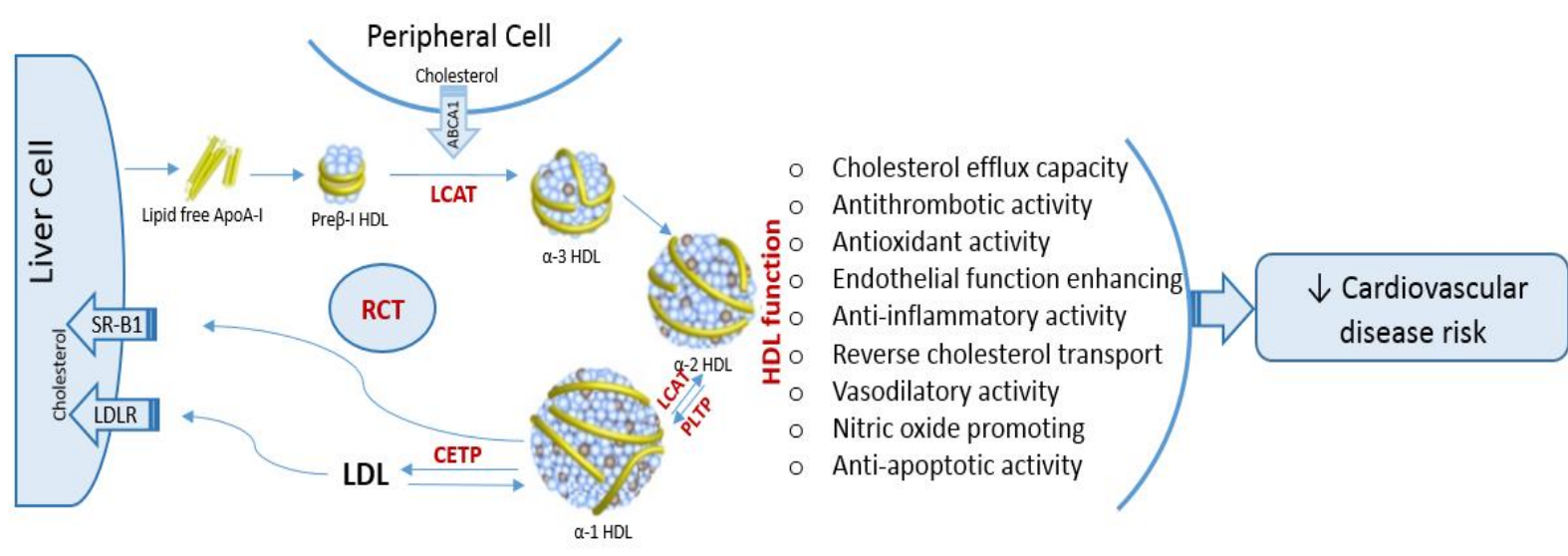

شكل r- عملكردهاى متنوع ليبويروتئين با جُعَالى بالا (HDL)، مهمترين عملكرد HDL انتقال كلسترول اضافى از بافتها و هدايت آن به سمت كبد است

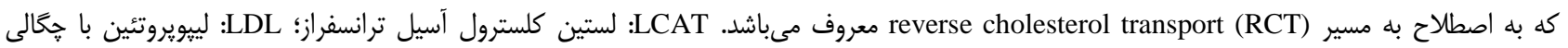

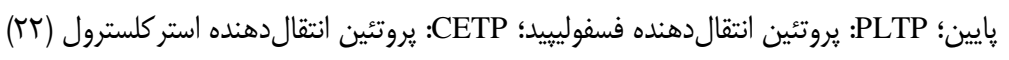

محتواى آيولييويروتئينهاى آنهاست (سب). مطالعات اوليه نشان داده است كه ذرات HDL بزركتر، اثر محافظتى بيشتر

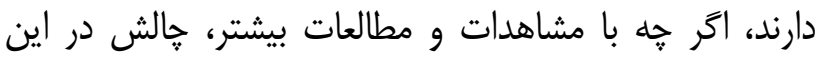

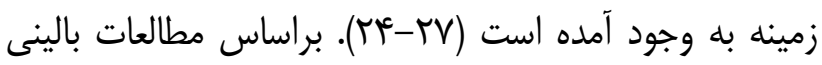
كه به بررسى اثرات مهاركنندههاى CETP (يروتئينهاى

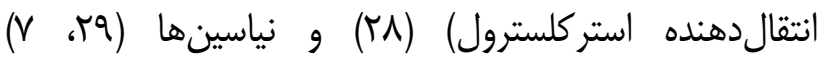
يرداختهاند، كاهش معنىدارى در خطر بيمارىهاى قلبى -

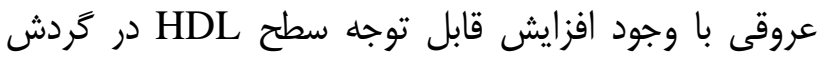

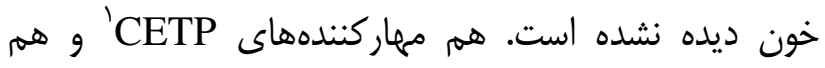

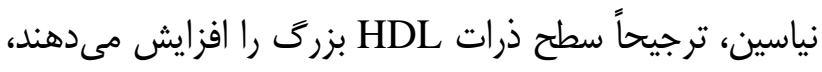

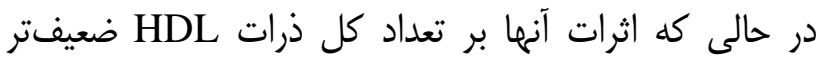

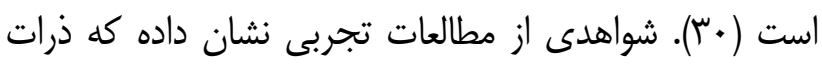

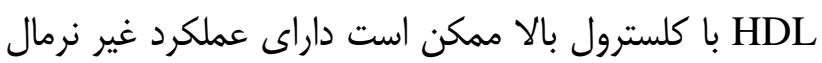

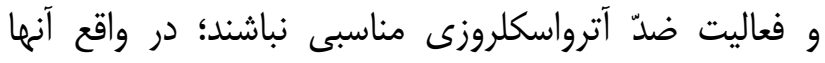

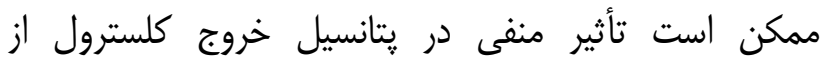
سلولهاى خارج كبدى و همجنين كاهش در جذب كلئ كلسترول

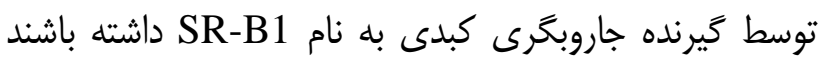

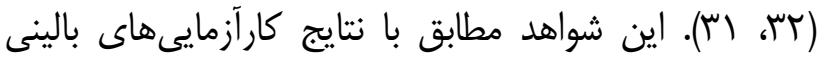

${ }^{1}$ Cholesteryl ester transfer protein
انجام مى گيرد. تحريك توليد اين آنزيهم توسط HDL، در

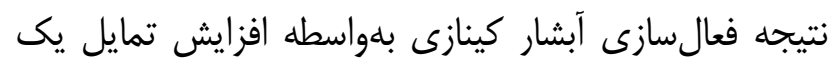

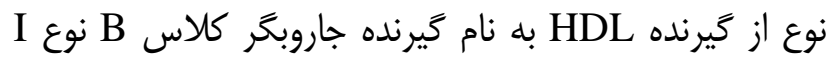

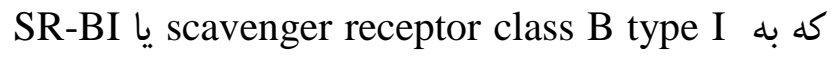

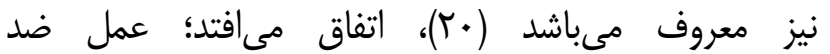
ترومبوتيكى آن نيز از طريق فعال سازى يروستاسايكلين سنتاز و همجنين از طريق كاهش بيان فاكتورهاى بافتى و سلكتين صورت مى گيرد كه در نتيجه، سبب تعديل متعاقب توليد

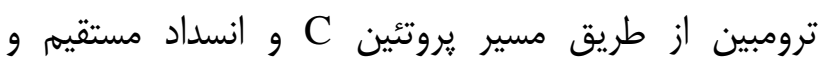

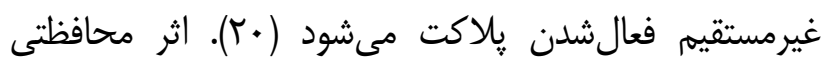
سلولى HDL يا به اصطلاح

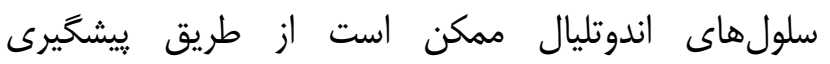

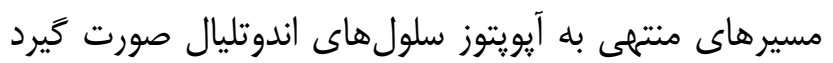

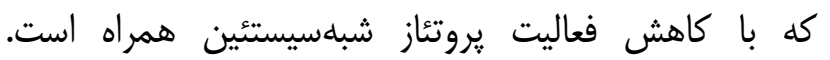
بنابراين HDL نقش محافظتى در برابر آسيب سلولى ايفا مى كند (r) بارين همانطور كه قبلاً اشاره شد، HDL ناهمگنى از ذرات با ساختار و فعاليت بيولوزيكى متنوع تشكيل

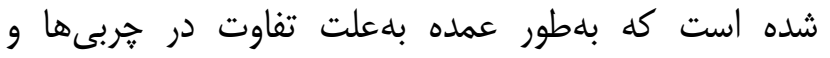


تأثير مى گذارند، برجسته مى كند (عس).

r- روشهاى اندازهكيرى HDL در تشخيص بيمارىهاى قلبى - عروقى:

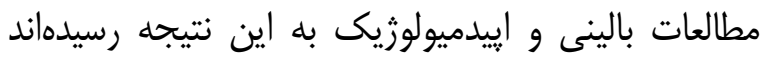

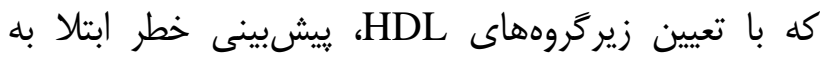
بيمارىهاى قلبى - عروقى بهتر صورت مى گيرد (هو). با توجه

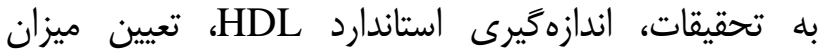

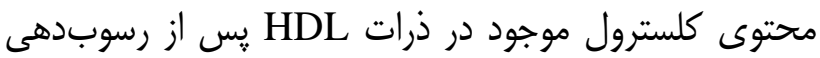
لييويروتئينهاى حاوى ApoB مى باشد. تكنيكهاى مورد استفاده براى تعيين سطح HDL سرم و اندازه آنها شامل:

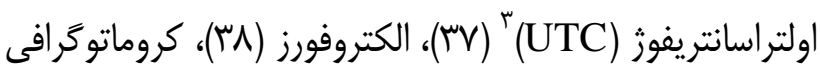

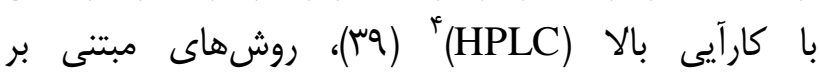

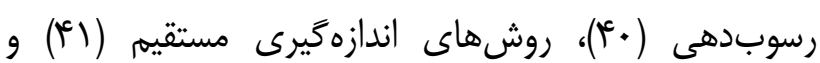

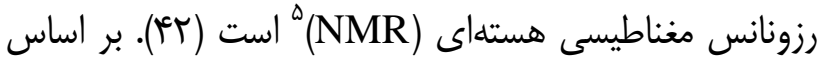
مطالعات انجامشده، سطح HDL-2 كه توسط الكتروفورز زل

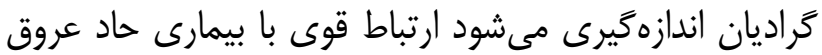

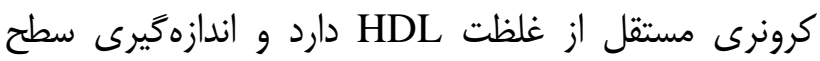

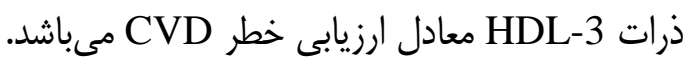

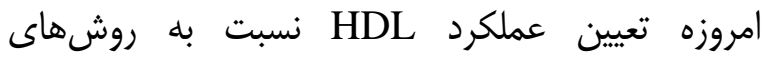
توصيفى كه تنها غلظت HDL را بررسى مى كنند بيشتر مورد توجه دانشمندان قرار گرفته است و گاهى اوقات تبديل به به هالش در اين زمينه شده است. در مطالعات نشان داده شده

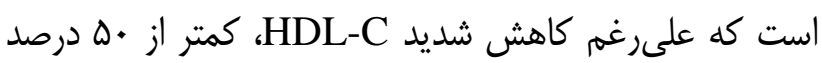

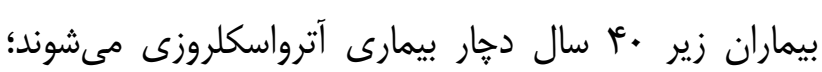

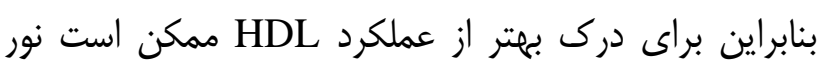

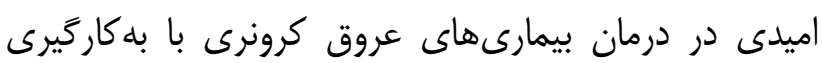

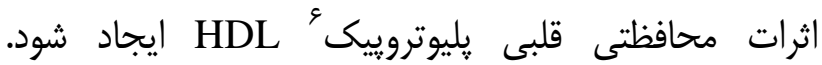
روشهاى متعددى براى اندازهيرى عملكرد HDL دارد از جمله: تعيين آنزيم ليستين كلسترول آسيل ترانسفراز

\footnotetext{
${ }^{3}$ Ultra-centrifuge

${ }^{4}$ High-performance liquid chromatography

${ }^{5}$ Nuclear magnetic resonance

${ }^{6}$ Pleiotropy
}

مىباشد كه در آنها نشان داده شده است سطح HDL-C بسيار بالا (mo/dL V•Z) و ذرات

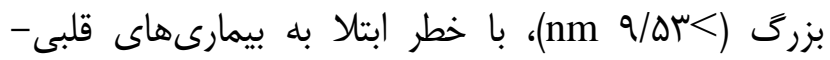

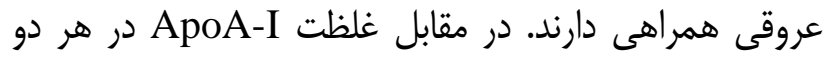
مطالعه سطح برابرى را نشان داده و اين مسئله را اثبات

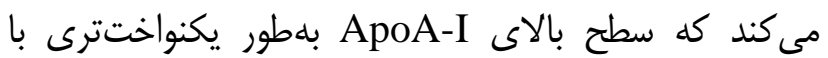
كاهش خطر ابتلا به بيمارىهاى قلبى - عروقى همراهى دارد

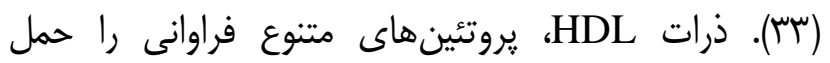
مى كنند كه نهتنها در متابوليسم ليبيدى اثر دارند بلكه در دران

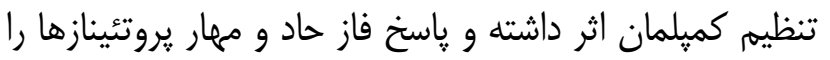
منجر مىشود. اين تنوع شامل: AppoC-II A ApoC-I، AppoE،ApoC-III

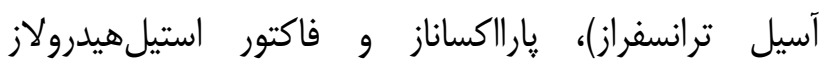

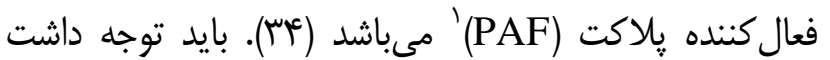

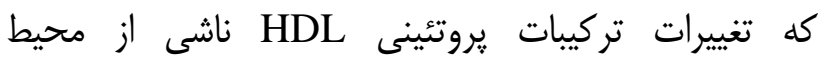

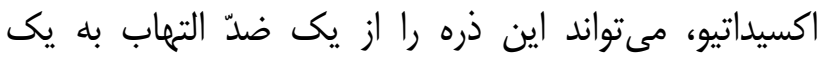

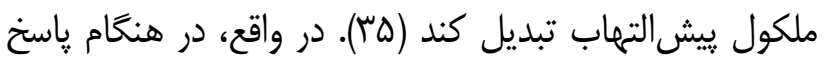

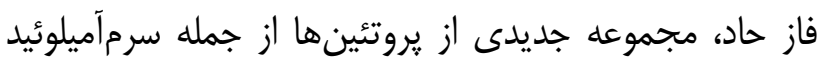
' و سرولويلاسمين به HDLA)

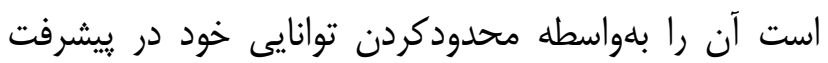
و و جلو عيرى از اصلاح تغييرات LDL يك ذره HDL بيشالتهابى و ويشيشاتروزنيك تبديل كند

تغذيه نيز يكى از عواملى است كه نقش مهرى در عملكرد HDL دارد؛ به طورى كه در مطالعات متعدد نشان داده شده است كه مصرف جربىهاى اشباع، سبب كاهش

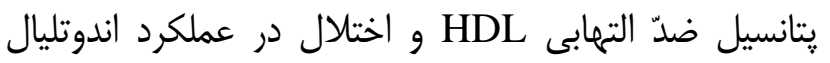

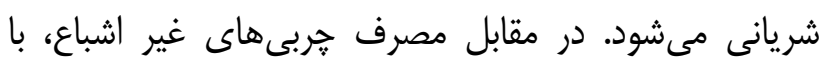

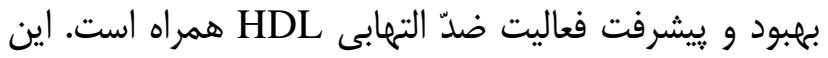

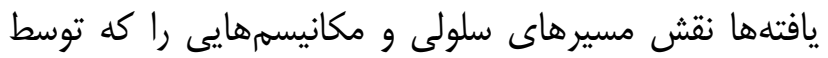

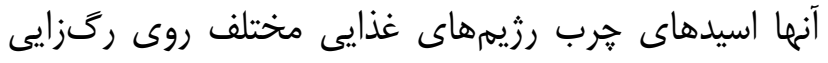




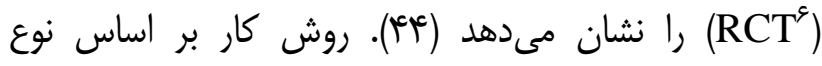

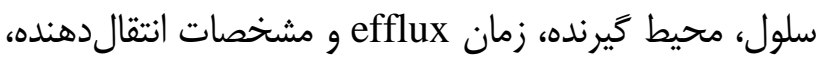

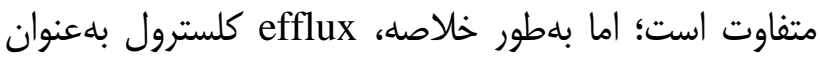

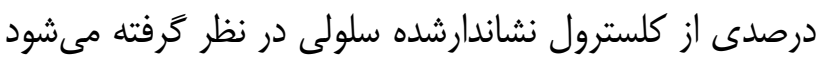

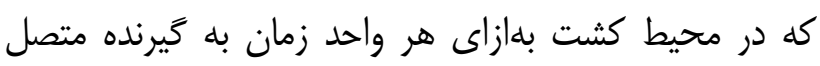

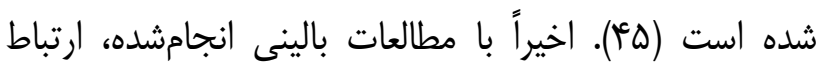

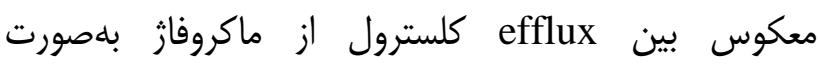
In vitro

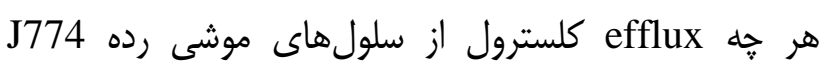

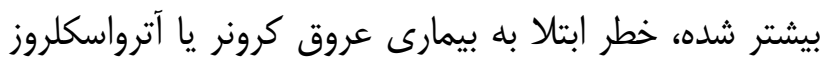

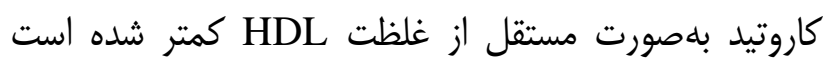

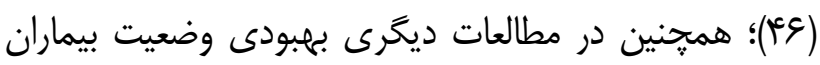

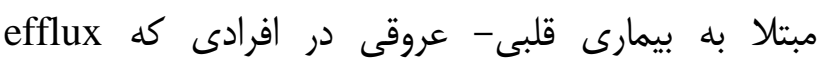

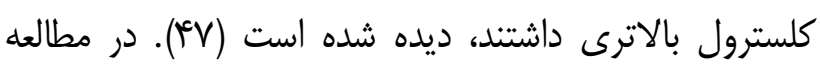

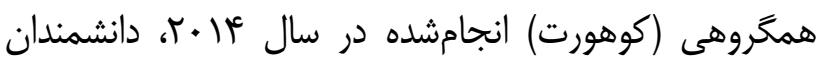

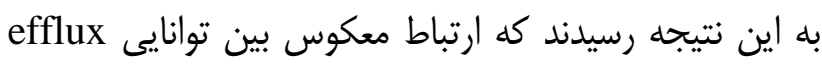

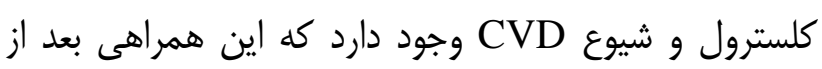

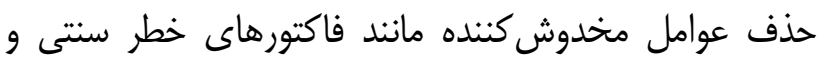

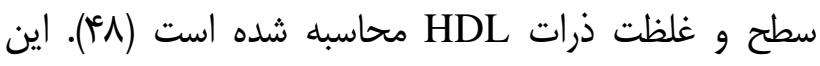
اطلاعات و يافتهها در آينده مىتواند براى توليد داروهايى كه دانه

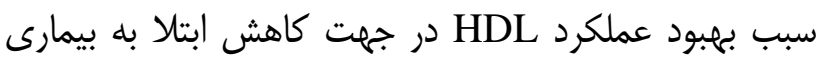
قلبى - عروقى مىشود، مورد استفاده قرار گيرد.

\section{نتيجه كيرى}

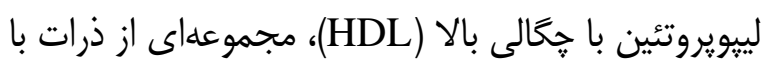

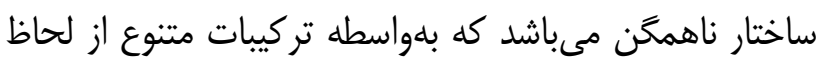

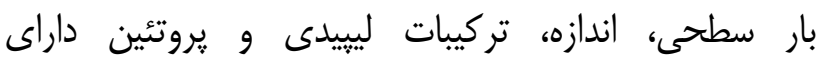
عملكردهاى متفاوتى هستند. بر اساس مطالعات ييشين، رابطه

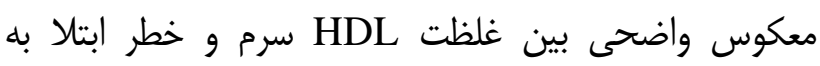

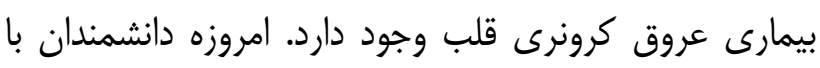

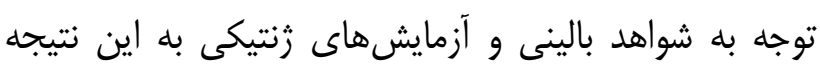

${ }^{6}$ Reverse cholesterol transport
(LCAT') كالسرو كلسترول توسط Uptake cholesterol) HDL)، تعيين عملكرد ضد التهابى Anti-inflammatory) HDL)، تعيين ظرفيت آنتىاكسيدانى (Antioxidant) HDL)، سنجش النش ICAM/VCAM اندوتليال عروقى و سنجش eNOS

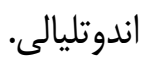

از مهمترين عملكردهاى HDL كه امروزه مطالعات و

آزمايشهاى زيادى براى تعيين آن انجام شدهد است أنسات I Efflux Cholesterol

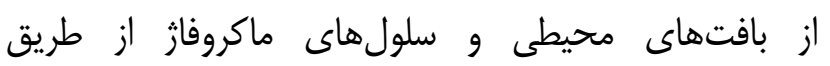

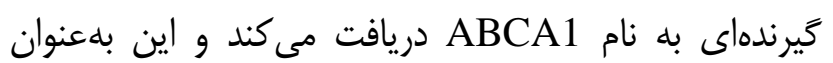

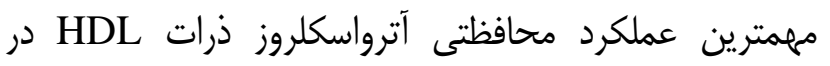

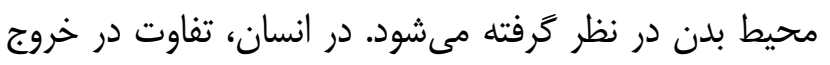

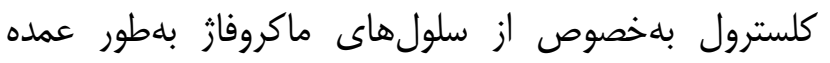

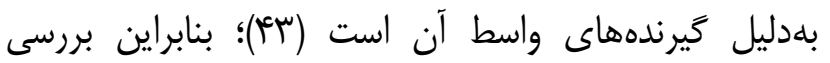

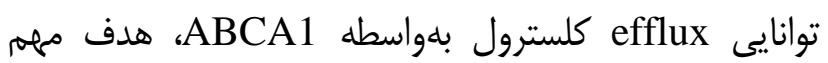

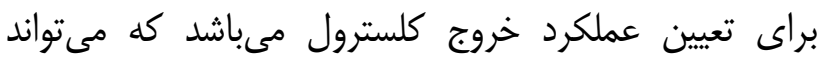
اهميت زيادى در ارزيابى خطر آترواسكلروز ايجاد كند. شايان

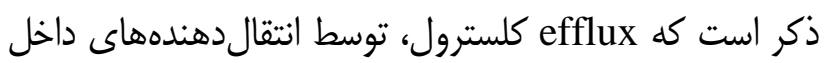

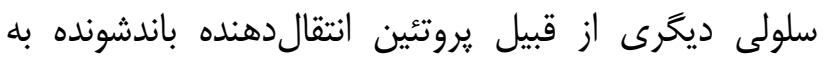

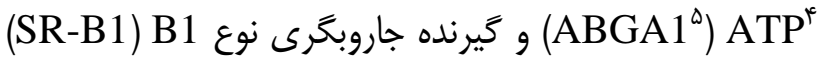
efflux تنظيم مىشود. روش راديواكتيوى اندازهيرى (B)

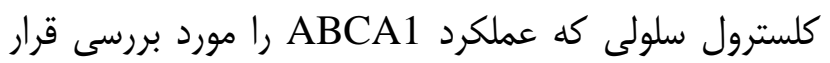

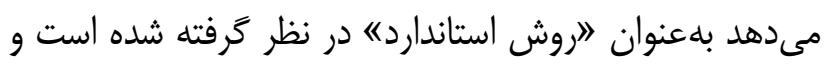

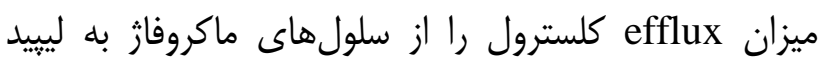

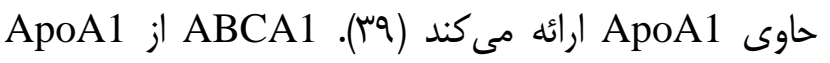

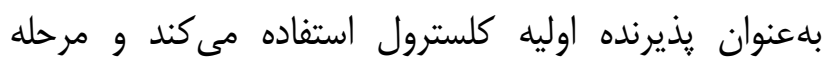
محدودكننده سرعت در مسير انتقال كلسترول معكوس الهئ

\footnotetext{
${ }^{1}$ Lecithin-Cholesterol Acyltransferase

${ }^{2}$ Endothelial nitric oxide synthase

${ }^{3}$ Intercellular Adhesion Molecule 1/vascular cell adhesion molecule 1

${ }^{4}$ Adenosine triphosphate

${ }^{5}$ ATP-binding cassette transporter A1
} 


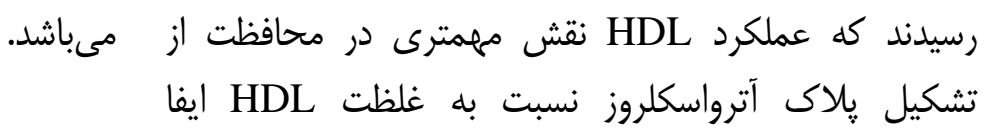

\section{تقلدير و تشكر}

بدينوسيله از همكاران محترم مركز تحقيقات بيمارىهاى قلب و عروق دانشگاه علوم يزشكى بيرجند كه ما را در انجام اين يثوهش يارى نمودند و همجنين از اساتيد محترم دانشگاه علوم يزشكى مشهر كه در اين نخارش همكارى داشتند،

$$
\text { صميمانه تشكر مى نمايم. }
$$

تضاد منافع

نويسندكان مقاله اعلام مىدارند كه هيج گَونه تضاد منافعى در يزوهش حاضر وجود ندارد.
مى كند. روشهاى متنوعى براى تعيين اندازه و عملكردهاى متفاوت HDL وجود دارد كه داراى مزايا و معايبى هستند. توانايى خروج كلسترول از ماكروفازها توسط HDL كه به (CEC) Cholesterol Efflux Capacity بطاح بروجة معروف است، يك معيار كليدى براى تعيين عملكرد HDL به شمار مىرود و يك رابطه معكوس قوى با ضخامت انتيمامديا كاروتيد و همجنين احتمال ابتلا به بيمارى عروق كرونرى آنزيوگرافى مستقل از سطح HDL دارد. بنابراين تحقيقات گسترده براى شناسايى عوامل و نشانخرهاى زيستى جديد و روش هاى اندازهگيرى جديد براى درى بهتر عملكرد و و كاهش خطر بيمارىهاى قلبى- عروقى مورد نياز منابع:

1- Kazemi T, Sharifzadeh G, Borna N. Geographical mortality distribution of cardiovascular diseases: first report from South Khorasan, Iran. Caspian J Intern Med. 2017; 8(1): 65-66.

2- Ortega LM, Materson BJ. Hypertension in peritoneal dialysis patients: epidemiology, pathogenesis, and treatment. J Am Soc Hypertens. 2011; 5(3): 128-36. doi: 10.1016/j.jash.2011.02.004.

3- Kazemi T, Hajihosseini M, Moossavi M, Hemmati M, Ziaee M. Cardiovascular risk factors and Atherogenic indices in an Iranian population: Birjand east of Iran. Clin Med Insights Cardiol. 2018; 12: 1179546818759286. DOI: $10.1177 / 1179546818759286$

4- März W, Kleber ME, Scharnagl H, Speer T, Zewinger S, Ritsch A, et al. HDL cholesterol: reappraisal of its clinical relevance. Clin Res Cardiol. 2017; 106(9): 663-75. doi: 10.1007/s00392-017-1106-1.

5- Siadat M, Kazemi T, Hajihosseni M. Cardiovascular Risk-Factors in the Eastern Iranian Population: Are We Approaching 25× 25 Target? J Res Health Sci. 2016; 16(1): 51-2.

6- Voight BF, Peloso GM, Orho-Melander M, Frikke-Schmidt R, Barbalic M, Jensen MK, et al. Plasma HDL cholesterol and risk of myocardial infarction: a mendelian randomisation study. Lancet. 2012; 380(9841): 572-80. doi: 10.1016/S0140-6736(12)60312-2

7- The HPS2-THRIVE Collaborative Group. Effects of extended-release niacin with laropiprant in high-risk patients. N Engl J Med. 2014; 371(3): 203-12. doi: 10.1056/NEJMoa1300955

8- Schwartz GG, Olsson AG, Abt M, Ballantyne CM, Barter PJ, Brumm J, et al. Effects of dalcetrapib in patients with a recent acute coronary syndrome. N Engl J Med. 2012; 367(22): 2089-99. doi: 10.1056/NEJMoa1206797.

9- Navab M, Reddy ST, Van Lenten BJ, Anantharamaiah GM, Fogelman AM. The role of dysfunctional HDL in atherosclerosis. J Lipid Res. 2009; 50(Suppl):S145-9. doi: 10.1194/jlr.R800036-JLR200.

10- Freeman LA. Native-native 2D gel electrophoresis for HDL subpopulation analysis. In: Freeman L. (eds) Lipoproteins and Cardiovascular Disease. Methods in Molecular Biology (Methods and Protocols). Totowa, NJ: Humana Press; 2013. vol 1027. pp: 353-67. doi: 10.1007/978-1-60327-369-5_17

11- Tailleux A, Fruchart J, Parkes J. HDL heterogeneity and atherosclerosis. Crit Rev Clin Lab Sci. 1996; 33(3): 163201. doi: 10.3109/10408369609083060

12- Rader DJ. Molecular regulation of HDL metabolism and function: implications for novel therapies. J Clin Invest. 2006; 116(12): 3090-100. doi: 10.1172/JCI30163. 
13- Vaisar T, Pennathur S, Green PS, Gharib SA, Hoofnagle AN, Cheung MC, et al. Shotgun proteomics implicates protease inhibition and complement activation in the antiinflammatory properties of HDL. J Clin Invest. 2007; 117(3): 746-56. doi: 10.1172/JCI26206

14- Kontush A, Lhomme M, Chapman MJ. Unraveling the complexities of the HDL lipidome. J Lipid Res. 2013; 54(11): 2950-63. doi: 10.1194/jlr.R036095

15- Toth PP. Reverse cholesterol transport: high-density lipoprotein's magnificent mile. Curr Atheroscler Rep. 2003; 5(5): 386-93. doi: 10.1007/s11883-003-0010-5.

16- Ansell BJ, Watson KE, Fogelman AM, Navab M, Fonarow GC. High-density lipoprotein function: recent advances. J Am Coll Cardiol. 2005; 46(10): 1792-8. doi: 10.1016/j.jacc.2005.06.080.

17- Connelly MA, Shalaurova I, Otvos JD. High-density lipoprotein and inflammation in cardiovascular disease. Transl Res. 2016; 173: 7-18. doi: 10.1016/j.trsl.2016.01.006.

18- Kontush A, Chapman MJ. Antiatherogenic function of HDL particle subpopulations: focus on antioxidative activities. Curr Opin Lipidol. 2010; 21(4): 312-8. doi: 10.1097/MOL.0b013e32833bcdc1.

19- Barter PJ, Nicholls S, Rye KA, Anantharamaiah G, Navab M, Fogelman AM. Antiinflammatory properties of HDL. Circ Res. 2004; 95(8): 764-72. doi: 10.1161/01.RES.0000146094.59640.13

20- Mineo C, Deguchi H, Griffin JH, Shaul PW. Endothelial and antithrombotic actions of HDL. Circ Res. 2006; 98(11): 1352-64. doi: 10.1161/01.RES.0000225982.01988.93

21- Sugano M, Tsuchida K, Makino N. High-density lipoproteins protect endothelial cells from tumor necrosis factor- $\alpha-$ induced apoptosis. Biochem Biophys Res Commun. 2000; 272(3): 872-6. doi: 10.1161/01.RES.0000225982.01988.93

22- Heinecke JW. A new era for quantifying HDL and cardiovascular risk? Nat Med. 2012; 18(9): 1346-7. doi: $10.1038 / \mathrm{nm} .2930$

23- Kosmas CE, Christodoulidis G, Cheng JW, Lerakis S, Vittorio TJ. High-density lipoprotein functionality in coronary artery disease. Am J Med Sci. 2014; 347(6): 504-8. doi: 10.1097/MAJ.0000000000000231.

24- Salonen JT, Salonen R, Seppänen K, Rauramaa R, Tuomilehto J. HDL, HDL2, and HDL3 subfractions, and the risk of acute myocardial infarction. A prospective population study in eastern Finnish men. Circulation. 1991; 84(1): 12939. doi: 10.1161/01.cir.84.1.129.

25- Drexel H, Amann FW, Rentsch K, Neuenschwander C, Luethy A, Khan SI, et al. Relation of the level of highdensity lipoprotein subfractions to the presence and extent of coronary artery disease. Am J Cardiol. 1992; 70(4): 43640. doi: 10.1016/0002-9149(92)91186-8.

26- Freedman DS, Otvos JD, Jeyarajah EJ, Barboriak JJ, Anderson AJ, Walker JA. Relation of lipoprotein subclasses as measured by proton nuclear magnetic resonance spectroscopy to coronary artery disease. Arterioscler Thromb Vasc Biol. 1998; 18(7): 1046-53. doi: 10.1161/01.atv.18.7.1046.

27- Rosenson RS, Otvos JD, Freedman DS. Relations of lipoprotein subclass levels and low-density lipoprotein size to progression of coronary artery disease in the Pravastatin Limitation of Atherosclerosis in the Coronary Arteries (PLACI) trial. Am J Cardiol. 2002; 90(2): 89-94. doi: 10.1016/s0002-9149(02)02427-x.

28- HPS3/TIMI55-REVEAL Collaborative Group; Bowman L, Hopewell JC, Chen F, Wallendszus K, Stevens W, Collins R, et al. Effects of anacetrapib in patients with atherosclerotic vascular disease. New England Journal of Medicine. 2017; 377(13): 1217-27. doi: 10.1056/NEJMoa1706444

29- AIM-HIGH Investigators; Boden WE, Probstfield JL, Anderson T, Chaitman BR, Desvignes-Nickens P, Koprowicz $\mathrm{K}$, et al. Niacin in patients with low HDL cholesterol levels receiving intensive statin therapy. New N Engl J Med. 2011; 365(24): 2255-67. doi: 10.1056/NEJMoa1107579.

30- Kontush A. HDL particle number and size as predictors of cardiovascular disease. Front Pharmacol. 2015; 6: 218. doi:10.3389/fphar.2015.00218

31- Ishigami M, Yamashita S, Sakai N, Arai T, Hirano KI, Hiraoka H, et al. Large and cholesteryl ester-rich highdensity lipoproteins in cholesteryl ester transfer protein (CETP) deficiency can not protect macrophages from cholesterol accumulation induced by acetylated low-density lipoproteins. J Biochem. 1994; 116(2): 257-62. doi: 10.1093/oxfordjournals.jbchem.a124516 
32- Qi Y, Fan J, Liu J, Wang W, Wang M, Sun J, et al. Cholesterol-overloaded HDL particles are independently associated with progression of carotid atherosclerosis in a cardiovascular disease-free population: a community-based cohort study. J Am Coll Cardiol. 2015; 65(4): 355-63. doi: 10.1016/j.jacc.2014.11.019.

33- van der Steeg WA, Holme I, Boekholdt SM, Larsen ML, Lindahl C, Stroes ES, et al. High-density lipoprotein cholesterol, high-density lipoprotein particle size, and apolipoprotein AI: significance for cardiovascular risk: the IDEAL and EPIC-Norfolk studies. J Am Coll Cardiol. 2008; 51(6): 634-42. doi: 10.1016/j.jacc.2007.09.060.

34- Van Lenten BJ, Navab M, Shih D, Fogelman AM, Lusis AJ. The role of high-density lipoproteins in oxidation and inflammation. Trends Cardiovasc Med. 2001; 11(3-4): 155-61. doi: 10.1016/S1050-1738(01)00095-0

35- Navab M, Reddy ST, Van Lenten BJ, Fogelman AM. HDL and cardiovascular disease: atherogenic and atheroprotective mechanisms. Nat Rev Cardiol. 2011; 8(4): 222-32. doi: 10.1038/nrcardio.2010.222.

36- Nicholls SJ, Lundman P, Harmer JA, Cutri B, Griffiths KA, Rye KA, et al. Consumption of saturated fat impairs the anti-inflammatory properties of high-density lipoproteins and endothelial function. J Am Coll Cardiol. 2006; 48(4): 715-20. doi: 10.1016/j.jacc.2006.04.080

37- Chapman MJ, Goldstein S, Lagrange D, Laplaud PM. A density gradient ultracentrifugal procedure for the isolation of the major lipoprotein classes from human serum. J Lipid Res. 1981; 22(2): 339-58.

38- Johansson J, Carlson LA, Landou C, Hamsten A. High density lipoproteins and coronary atherosclerosis. A strong inverse relation with the largest particles is confined to normotriglyceridemic patients. Arterioscler Thromb. 1991; 11(1): 174-82. doi: 10.1161/01.atv.11.1.174.

39- Asztalos BF, Collins D, Horvath KV, Bloomfield HE, Robins SJ, Schaefer EJ. Relation of gemfibrozil treatment and high-density lipoprotein subpopulation profile with cardiovascular events in the Veterans Affairs High-Density Lipoprotein Intervention Trial. Metabolism. 2008; 57(1): 77-83. doi: 10.1161/01.atv.11.1.174.

40- Warnick GR, Albers J. A comprehensive evaluation of the heparin-manganese precipitation procedure for estimating high density lipoprotein cholesterol. J Lipid Res. 1978; 19(1): 65-76.

41- Warnick GR, Nauck M, Rifai N. Evolution of methods for measurement of HDL-cholesterol: from ultracentrifugation to homogeneous assays. Clin Chem. 2001; 47(9): 1579-96.

42- AACC Lipoproteins and Vascular Diseases Division Working Group on Best Practices; Cole TG, Contois JH, Csako G, McConnell JP, Remaley AT, Devaraj S, et al. Association of apolipoprotein B and nuclear magnetic resonance spectroscopy-derived LDL particle number with outcomes in 25 clinical studies: assessment by the AACC lipoprotein and vascular diseases division working group on best practices. Clin Chem. 2013; 59(5): 752-70. doi: 10.1373/clinchem.2012.196733.

43- de la Llera-Moya M, Drazul-Schrader D, Asztalos BF, Cuchel M, Rader DJ, Rothblat GH. The ability to promote efflux via ABCA1 determines the capacity of serum specimens with similar high-density lipoprotein cholesterol to remove cholesterol from macrophages. Arterioscler Thromb Vasc Biol. 2010; 30(4): 796-801. doi: 10.1161/ATVBAHA.109.199158.

44- Alrasadi K, Awan Z, Alwaili K, Ruel I, Hafiane A, Krimbou L, et al. Comparison of treatment of severe highdensity lipoprotein cholesterol deficiency in men with daily atorvastatin $(20 \mathrm{mg})$ versus fenofibrate $(200 \mathrm{mg})$ versus extended-release niacin (2 g). Am J Cardiol. 2008; 102(10): 1341-7. DOI: 10.1016/j.amjcard.2008.07.010

45- Rothblat G, De La Llera-Moya M, Favari E, Yancey P, Kellner-Weibel G. Cellular cholesterol flux studies: methodological considerations. Atherosclerosis. 2002; 163(1): 1-8. doi: 10.1016/s0021-9150(01)00713-4.

46- de la Llera Moya M, McGillicuddy FC, Hinkle CC, Byrne M, Joshi MR, Nguyen V, et al. Inflammation modulates human HDL composition and function in vivo. Atherosclerosis. 2012; 222(2): 390-4. doi: 10.1016/j.atherosclerosis.2012.02.032.

47- Li XM, Wilson Tang WH, Mosior MK, Huang Y, Wu Y, Matter W, et al. Paradoxical association of enhanced cholesterol efflux with increased incident cardiovascular risks. Arterioscler Thromb Vasc Biol. 2013; 33(7):1696-705. doi: 10.1161/ATVBAHA.113.301373.

48- Rohatgi A, Khera A, Berry JD, Givens EG, Ayers CR, Wedin KE, et al. HDL cholesterol efflux capacity and incident cardiovascular events. N Engl J Med. 2014; 371(25): 2383-93. doi: 10.1056/NEJMoa1409065. 